\title{
Sleep disorders, sleepiness and traffic safety: a public health menace
}

S.R. Pandi-Perumal ${ }^{1}$, J.C. Verster ${ }^{2}$, L. Kayumov ${ }^{3}$, A.D. Lowe ${ }^{3}$, M.G. Santana ${ }^{4}$, M.L.N. Pires ${ }^{4}$, S. Tufik ${ }^{4}$ and M.T. Mello 4

\section{Correspondence \\ S.R. Pandi-Perumal \\ Division of Pulmonary, Critical \\ Care, and Sleep Medicine \\ Mount Sinai School of Medicine \\ One Gustave L. Levy Place \\ Box \#1232 \\ New York, NY 10029 \\ USA \\ E-mail: pandiperumal@gmail.com \\ or \\ M.T. de Mello \\ Rua Marselhesa, 535 \\ 04020-060 São Paulo, SP \\ Brasil \\ E-mail: tmello@ psicobio.epm.br}

Research supported by Associação

Fundo de Incentivo à Psicofarmacologia

and FAPESP/CEPID (No. 98/14303-3).

....................

Received October 27, 2005

Accepted April 20, 2006

\author{
${ }^{1}$ Division of Pulmonary, Critical Care, and Sleep Medicine, \\ Mount Sinai School of Medicine, New York, NY, USA \\ ${ }^{2}$ Department of Psychopharmacology, Utrecht Institute for Pharmaceutical Sciences, \\ University of Utrecht, U trecht, The Netherlands \\ ${ }^{3}$ Department of Psychiatry, University of Toronto, and Sleep and Neuropsychiatry \\ Institute, Scarborough, ON, Canada \\ ${ }^{4}$ Departamento de Psicobiologia, Universidade Federal de São Paulo, São Paulo, \\ $\mathrm{SP}$, Brasil
}

\section{Abstract}

Sleep disorders are not uncommon and have been widely reported throughout the world. They have a profound impact on industrialized 24-h societies. Consequences of these problems include impaired social and recreational activities, increased human errors, loss of productivity, and elevated risk of accidents. Conditions such as acute and chronic insomnia, sleep loss, excessive sleepiness, shift-work, jet lag, narcolepsy, and sleep apnea warrant public health attention, since residual sleepiness during the day may affect performance of daily activities such as driving a car. Benzodiazepine hypnotics and zopiclone promote sleep, both having residual effects the following day including sleepiness and reduced alertness. In contrast, the non-benzodiazepine hypnotics zolpidem and zaleplon have no significant next-day residual effects when taken as recommended. Research on the effects of wakefulness-promoting drugs on driving ability is limited. Countermeasures for excessive daytime sleepiness have a limited effect. There is a need for a social awareness program to educate the public about the potential consequences of various sleep disorders such as narcolepsy, sleep apnea, shift-work-related sleep loss, and excessive daytime sleepiness in order to reduce the number of sleep-related traffic accidents.

\section{Introduction}

There is a lack of awareness among the public and among physicians and authorities in general of the problem posed by sleepy drivers. Every year about $20-40 \%$ of American adults have difficulty sleeping and $17 \%$ consider the problem serious (1). According to the National Sleep Foundation Gallup Survey, 63 million adults have sleep levels

\section{Key words}

- Sleep disorders

- Sleepiness

- Automobile and truck drivers

- Automobile traffic

- Public health considered to be hazardous to their wellbeing, with $6 \%$ experiencing severe levels of sleepiness (2). In addition, $12 \%$ of senior citizens report chronic insomnia, and this estimate is even higher among those with concomitant medical or psychiatric illnesses (3). The 2002 Sleep in America Poll (4) revealed that $37 \%$ of adults reported that daytime sleepiness interfered significantly with their daily activities. Hence, today in- 
somnia can be considered to be one of the most prevalent public health problems.

The concept of sleep has changed dramatically in modern 24 -h society. Time asleep is viewed as wasted time, and spending many hours sleeping is often associated with laziness. Although sleep problems are experienced as inconvenient, they are often not viewed as a medical problem. Hence, only a minority of persons with sleep disturbances consult their physicians and receive medical attention. Nevertheless, it is generally acknowledged that poor sleep quality may result in reduced quality of life. Excessive daytime sleepiness is one of the major complaints of people with sleep disturbances since it may be reflected in altered mood and behavioral impairment. Reduced performance becomes of public concern when subjects with excessive daytime sleepiness are involved in potentially dangerous daily activities such as driving a car.

\section{Road safety: an issue attracting increased global attention}

Road safety is an important issue that has recently attracted increased attention from the United Nations and the World Health Organization (5). In 1998, over 1.2 million persons worldwide were killed in road traffic accidents, making road traffic accidents the 10th leading cause of death. A multiple number of persons were injured by road traffic accidents and became disabled. The medical and economic costs of traffic accident-related injuries and disabilities are estimated to equal 1 to $3 \%$ of a country's gross national product (global yearly costs of 518 billion US dollars). In 2020, the number of persons killed in road traffic accidents is expected to nearly double to 2.3 million deaths worldwide. In August 2003, the United Nations acknowledged the global road safety crisis by urging their member states that "traffic accidents now pose a global public health crisis that requires urgent action at the national and the international levels". In addition, the WHO's annual World Health Day (April 7, 2004) was dedicated to Road Safety. This article will discuss the impact of sleepiness, sleep disorders and their pharmacological treatments on traffic safety. Recommendations are given for future research and public health policies.

\section{Sleepiness and driving safety}

There is a considerable body of evidence that sleepiness contributes to the cause of various accidents in industries and in transport systems (6). A recent study (7) examined 1828 road traffic crashes on 15 different roads in the UK. The authors reported that $17 \%$ of the traffic accidents resulting in death or injury were sleep related. This percentage varied between 3 and 30\% depending on the road type. Sleepiness-related accidents were especially prevalent during the early morning hours and 50\% more likely than normal crashes to result in serious injury or death.

The 2002 Gallup survey (8) revealed that $37 \%$ of drivers reported that they have nodded off or fallen asleep at least once in their driving career. The Sleep in America Poll (4) revealed that $91 \%$ of subjects agreed that not getting enough sleep puts a person at risk for injuries, but $51 \%$ of the respondents reported that they did drive while sleepy.

The characteristics of these drowsy drivers include having less than $6 \mathrm{~h}$ of sleep the previous night, driving for more than $2.9 \mathrm{~h}$, driving on an interstate highway, and driving in the dark (between 9:00 pm and 6:00 am). In this context, truck drivers reported that their actual sleeping time was significantly less than the desired period of sleep (5.18 vs 7.1 h). Encephalographic determinations during driving confirmed that these truck drivers slept less than required to be alert (9).

The relationship between factors causing sleepiness and reduced driving ability is sum- 
marized in Figure 1. It is evident from Figure 1 that both endogenous factors (individual characteristics) and external factors (task and environment-related) contribute to sleepiness, which in turn may result in poor driving performance.

\section{Endogenous factors}

Sleep-related disturbances that have been related to increased traffic accident risks include excessive daytime sleepiness (6), inattention due to sleepiness (10), obstructive sleep apnea (11), narcolepsy (12), sleep deprivation (sleep curtailment) (13), poor sleep hygiene (13), changes in wakefulnesssleep circadian rhythm (7), sudden "sleep attacks", "dozing off" or "micro sleep" (14), and the use of sleep medication (15).

\section{Alcohol}

On-the-road tests during normal traffic showed that the driving performance of healthy subjects is significantly impaired after administration of alcohol yielding blood alcohol levels below $0.05 \%$ (16). Driving tests on a closed-circuit showed that the effects of alcohol (blood alcohol concentration $=0.089 \%$ ) on driving performance were comparable to those of sleep deprivation (17). The impairing effects of alcohol on simulated driving have ben shown to be exacerbated in sleepy drivers (18). Another study quantified this impairment, showing that after 18.5 and $21 \mathrm{~h}$ of wakefulness, driving impairment in a simulator was comparable to that observed in drivers with blood alcohol concentrations of 0.05 and $0.08 \%$, respectively (19). Hence, even low-dose alcohol use should be avoided by sleepy drivers.

\section{External factors}

The impact of sleepiness on driving safety also depends on exogenous factors such as irregular working hours, duration of driving and total working hours (20). It is important to point out that usually human efficiency decreases in individuals who continue to work after being aware of their fatigue (21).
Characteristics of the individuals

$$
\begin{aligned}
& \text { - Natural sleep-wake rhythm } \\
& \text { - Sleep hygiene } \\
& \text { - Sleep debt/deprivation } \\
& \text { - Sleep inertia } \\
& \text { - Use of sleep medication }
\end{aligned}
$$

\section{External factors}

- Monotonousness of task

- Monotonousness of environment

- Time on task

- Time of day

\section{SLEEPINESS}

Electrophysiological changes, physical symptoms, changes in attention and information processing, changes in sensation and perception, highway hypnosis, and microsleep

\section{REDUCED DRIVING PERFORMANCE}

Figure 1. Characteristics of the individual and external factors related to sleepiness that may result in reduced driving performance (adapted from Vesentini et al., 59). 
Several investigators have suggested that fatigue contributes as a cause of various accidents in industry and in transport systems $(15,22)$.

Mello et al. (23) conducted an epidemiological survey on 400 professional interstate bus drivers in Brazil and showed that accidents may be related to sleep problems since $16 \%$ of the drivers interviewed reported they had fallen asleep at the wheel, while 58\% knew some fellow driver who had also fallen asleep at the wheel. Drivers who admitted they had fallen asleep at the wheel while driving (16\%) reported a frequency of 8 such episodes per trip. More recently, Multiple Sleep Latency Tests revealed that 42 and $38 \%$ of a group of long-haul bus drivers working shifts met the criteria for excessive sleepiness when the test was conducted during the day and night, respectively, when the drivers normally would be working/driving (24). Taken together, these findings point out that drivers' ability to get sufficient sleep just prior to the driving hours appears to be reduced, and that they are sleepy during a time when they are expected to be alert. This is highly relevant since other studies have demonstrated the effects of sleepiness in terms of reduction of attention, memory, reaction time, problem solving, and cognition, leading to the risk of accidents (22).

\section{Highway versus city driving}

Prolonged stress situations associated with reduced vigilance (e.g., highway driving, in contrast to city driving) increase the conditions leading to accidents (25). In this context, it has been reported that in city driving increased traffic density produces increased numbers of sleepiness-related accidents, whereas in highway driving increased traffic density reduces the number of sleepiness-related accidents (7). The latter can be explained by the fact that highway driving is a monotonous task; the presence of other cars may trigger the attention of drivers and keep them more alert.

\section{Time of work}

Studies have indicated an increased risk of accidents as a function of time of work, i.e., about $9 \mathrm{~h}$ after the beginning of the work shift. This risk may increase 2-fold after $12 \mathrm{~h}$ of work and 3-fold after $14 \mathrm{~h}$ of continuous work $(22,26)$. Increased accident rates have been reported also after $5 \mathrm{~h}$ of continuous work (27) and in shift-working people (28).

\section{Shift-working and driving safety}

The relatively high rates of sleep disturbances and excessive daytime sleepiness can be attributed in part to the changed concept of sleep in the modern 24-h society. For example, about $20 \%$ of the workers in industrialized nations are shift workers (29), and $25 \%$ of the Canadian work force (30) and one third of the Swedish work force (31) are scheduled to be on shift work. Shift and night work has considerably increased over the last decade, mainly due to economic, demographic and technological changes (32).

Shift workers frequently complain that they are unable to sleep at irregular times and report problems related to sleepiness (33). Among factors that contribute to the complaint of sleepiness among shift workers are disorders such as obstructive sleep apnea, periodic leg movement syndrome, insomnia, and narcolepsy (34). Most human beings are active during the light phase, showing a greater propensity to rest and sleep during the dark phase. Thus, some changes in this pattern can lead to behavioral alterations especially with respect to sleep, representing a risk factor for an increased number of accidents and for worker health (35). This is illustrated by the fact that significantly more accidents are reported when driving home after a night shift compared to a day shift (28). 


\section{O bstructive sleep apnea/hypopnea syndrome and driving safety}

Sleep disordered breathing and sleepiness are more pronounced in professional drivers than in the general population (36). In Brazil, about $30 \%$ of truck drivers were found to be at high risk for sleep apnea (37) and almost $40 \%$ of the bus drivers met the criteria for obstructive sleep apnea/hypopnea syndrome (OSAHS) (22). Drivers with OSAHS have a significantly increased risk of traffic accidents than subjects without OSAHS (38). This may be related to the observation that drivers with OSAHS present reduced concentration and reaction time (39). A recent study reported that drivers with sleep apnea have a 7 -fold increased risk of injury when compared to healthy drivers (6).

There are other studies, however, that do not report increased traffic accident risks in drivers with sleep-disordered breathing (40). In this context, it should be noted that successful treatment of OSAHS significantly reduces the risk of traffic accident. For example, nasal continuous positive airway pressure treatment significantly reduces the rate of traffic accidents and daytime sleepiness of patients with OSAHS (38).

\section{Sleep medications and driving safety}

According to the Sleep in America Poll (4), $15 \%$ of the 1010 subjects interviewed reported using prescription hypnotics $(8 \%)$ or over-the-counter sleep aids (10\%). Among those subjects reporting daytime sleepiness, $22 \%$ used sleep medicine regularly.

A recent review of the literature shows that epidemiological findings of increased traffic accident risks for benzodiazepine users are supported by evidence from on-theroad driving studies (15). In the on-the-road driving test during normal traffic subjects operate an instrumented vehicle over a 100km highway circuit. Subjects are instructed to drive with a steady-lateral position within the right traffic lane, while maintaining a constant speed $(95 \mathrm{~km} / \mathrm{h})$. The primary parameter of the test is the standard deviation of lateral position $(\mathrm{cm})$, indexing the weaving of the car.

As is evident from Table 1, most benzodiazepine hypnotics produce driving impairment exceeding the common legal limits for driving when compared to blood alcohol concentrations (15). Zopiclone also produces significant driving impairment the morning following bedtime administration. In contrast, zolpidem and zaleplon do not affect driving ability when administered at bedtime.

It should be noted that the subjects who participated in these experimental studies enjoyed a full night of sleep. It is reasonable to assume that in sleep-deprived subjects or those experiencing disturbed sleep, the ef-

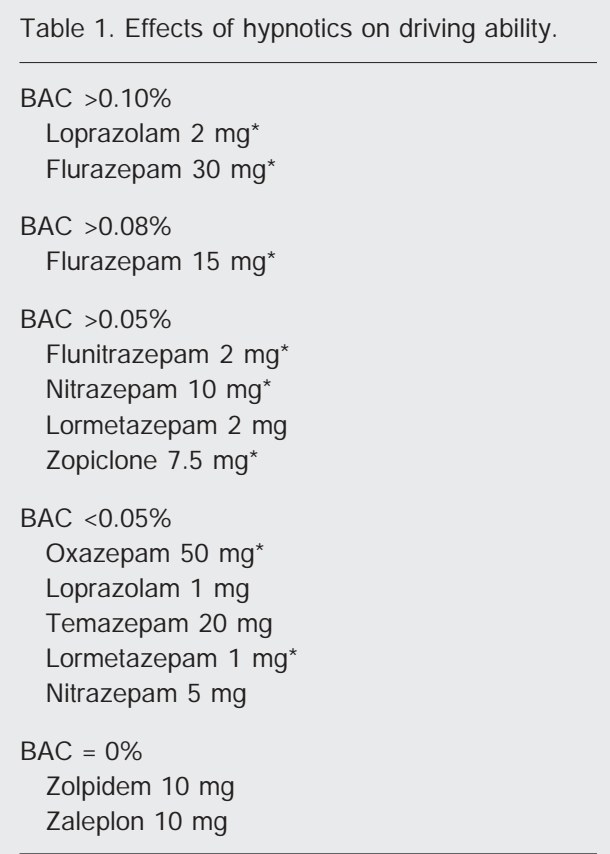

Driving tests were performed $10-11 \mathrm{~h}$ after bedtime administration. The results are compared with blood alcohol concentration (BAC) that corresponds to the most common legal limits for driving a car.

*Significantly different from placebo $(P<0.05$; ANOVA). 
fects of psychoactive drugs are much more pronounced.

\section{Counter-measures of sleepiness}

The Gallup survey (8) reported that most drivers stop the car to sleep (43\%) or rest $(15 \%)$ when they feel sleepy while driving. Other interventions reported by drivers include opening the window (26\%), drinking coffee $(17 \%)$, or playing the radio loudly (14\%). Unfortunately, except for stopping the car, these strategies provide little benefit.

\section{Educational measures}

Drivers should be aware of the importance of the physiological need for sleep, the detrimental effects of lack of sleep on performance, and of the dangers of inverted working and resting periods. Public awareness campaigns should inform the general public of the dangers of driving while sleepy.

\section{Behavioral measures}

According to Harma (41), there are individual differences such as domestic factors, age, sex, heredity, circadian phase, practice of sports, and ability to sleep which have been studied as factors contributing to a better adaptation to shift work.

Behavioral counter-measures that reduce the risk of motor vehicle collisions have been summarized by Cummings et al. (42) and can be summarized as follows: a) if the driver feels sleepy he should stop driving; b) efficient use of highway rest stops for bouts of naps; c) turning on a radio or music; d) getting enough rest prior to departure; e) avoiding long distance driving alone, but sharing the driving, or interrupting the trip.

\section{Napping}

Napping has been considered to be a possible strategy for increasing the level of alertness of night workers (43). The objective of this technique is to improve performance and alertness during the night of operational workers who execute the same task for a prolonged period of time (44), but its negative effect is sleep inertia (transient period that occurs immediately after awakening) immediately after a nap (45). This effect may differ according to the type of task and the technique used for reactivation immediately after awakening. However, sleep inertia depends on the quantity and quality of napping (46), the sleep stage that precedes awakening (47), the napping place (48), and the duration of awakening from a nap (49).

\section{Caffeine}

It has been shown that slow-release caffeine can be potentially exploited as a valuable counter-measure against reduced performance caused by sleep deprivation with no important side effects, especially when its application is of an acute nature and when there is no opportunity to take a nap (50). Caffeine has been used to contain sleep and has an effect similar to, although lower than, napping (51). When used at the beginning of the night and at various doses, caffeine increases alertness and improves psychomotor performance during the night, especially between 22:30 and 1:20 h. Rosekind et al. (44) reported that caffeine should be used during the window of circadian somnolence. However, caffeine can reduce, but not eliminate the sleep problems associated with alternate shift work (51).

\section{Pharmacological measures}

Reduced sleep quality and sleep duration have been reported to occur in shift-workers, possibly affecting performance after awakening. Shift workers may benefit from hypnotics to promote sleep during daytime. For example, relative to placebo, improved daytime sleep duration, sleep quality and 
psychomotor performance were reported for temazepam (52), zopiclone (53) and zolpi$\operatorname{dem}(54)$.

Similar results have been reported for persons traveling across time zones. For example, aircraft personnel has to adjust their sleeping hours to flight schedules. Hypnotics can be useful to facilitate sleep during the period from landing to flying back. After traveling across time zones, psychomotor performance was not significantly affected by temazepam and sleep quality and duration were significantly improved (55).

The Sleep in America Poll (4) showed that $6 \%$ of the subjects interviewed report that they have used medications to stay awake. Promising results have been reported for modafinil in reducing sleepiness (56); however, the effects of this drug on driving ability have not been determined.

\section{Physical exercise/physical activity}

The practice of physical exercise can help improve the quality and efficacy of sleep (57). In addition, depending on the period of the light-dark cycle (wakefulnesssleep) during which it is performed, it can cause an increase of central temperature which might, in turn, minimize sleep induction. However, its effects can be masked, and the temperature can quickly return to its basal values. Consequently, it is not recommended that sedentary individuals who are going to have their first session of physical training do so near their bedtime. Rather, they should do it 5 or $6 \mathrm{~h}$ before this time (58).

As a result, with this alteration (increase) of body temperature after the practice of moderate aerobic physical exercise (Ventilation Threshold 1 or 2), we could hypothesize that the elevation of body temperature could cause a reduction of sleep induction or of sleepiness, which could minimize the consequences of excessive sleepiness among shift workers, namely professional drivers.
Therefore, the practice of physical exercise at the beginning of the dark period could be an effective strategy to reduce the complaints of sleepiness in this population and, as a result, reduce the number of accidents caused by sleepiness. This hypothesis, however, should be studied more in depth, since information such as the chronotype, the kind of rotation in the work shifts, the total sleep time the worker needs to recover during his period of rest (considering whether this period is in the light or dark cycle, and whether the worker resorts to planned naps) is very important for any work schedule to be effective. Therefore, we should never observe only one variable when aiming at any kind of intervention in the work schedule.

As a result, sleep-related accidents are probably under-reported due to the lack of appropriate training of police officers. Even if the public acknowledges the deleterious effects of sleep behind the wheel, it fails to grant appropriate priority status to the problem. In this context, it is exemplary that driver training manuals do not mention a word about the dos and don'ts concerning sleepiness when driving.

In addition to regular drivers, this knowledge is especially important for professional drivers. The administrators of collective transport companies should be aware of data concerning sleep pattern, hygiene and disorders since factors such as sleep restriction or deprivation and habits related to the sleepwakefulness cycle are frequently related to reports of accidents associated with falling asleep at the wheel (13).

Also, a better planning of work shifts for shift workers is of fundamental importance (20) since positive results are obtained with this intervention. New strategies for biological adaptation of working hours should be examined and implemented in order to minimize accidents and to reduce sleepiness, to enable shift-workers to avoid driving during vulnerable periods of time of their work shift (20). Therefore, it is of crucial importance to 
conduct new studies using computerized polysomnography to determine in an objective manner the main sleep disorders of professional drivers in order to indicate the correct treatment for drivers presenting them. With basic knowledge about sleep, sleep disorders and chronobiology, the companies can adopt simple and low-cost measures to alter the work shift which will permit a better life style and safer driving for the workers and a probable improvement of the service the workers execute for the company.

\section{Research agenda}

There is a need for social awareness programs to educate the general population about the potential consequences of various sleep disorders such as narcolepsy, sleep apnea, shift-work-related sleepiness, sleep loss, and excessive somnolence. Such information should also be made available to the policy makers in both the public and industrial sectors.

Information on the impact of such public health issues should be made available to the healthcare sectors and should become a regular part of their training initiatives.

Sleep centers around the world should play a pivotal role in the assessment, diagnosis, training, treatment, and management of sleep disorders.

Examining the effects of sleep disorders and sleep-related problems should be tested preferably with on-the-road tests during normal traffic, since this testing methodology has a higher ecological validity than simulators and other laboratory tests.

Owing to the complexity of sleep problems and sleepiness and their effects on traffic safety such management programs should have a multidisciplinary and multidimensional approach.

\section{References}

1. Mellinger GD, Balter MB, Uhlenhuth $\mathrm{EH}$. Insomnia and its treatment. Prevalence and correlates. Arch Gen Psychiatry 1985; 42: 225-232.

2. Roth $T$, Ancoli-Israel S. Daytime consequences and correlates of insomnia in the United States: results of the 1991 National Sleep Foundation Survey. II. Sleep 1999; 22 (Suppl 2): S354-S358.

3. Ford DE, Kamerow DB. Epidemiologic study of sleep disturbances and psychiatric disorders. An opportunity for prevention? J AMA 1989; 262: 1479-1484.

4. National Sleep Foundation. 2002 Sleep in America Poll. Washington: National Sleep Foundation; 2002.

5. Peden M, Scurfield R, Sleet D, Mohan D, J ayder A, J arawan E, et al. World report on road traffic injury prevention. Geneva: World Health Organization; 2004.

6. Connor J, Whitlock G, Norton R, Jackson R. The role of driver sleepiness in car crashes: a systematic review of epidemiological studies. Accid Anal Prev 2001; 33: 31-41.

7. Flatley $D$, Reyner LA, Horne J A. Sleep related crashes on sections of different road types in the UK (1995-2001). London: Department of Transport, Road Safety Research Report No. 52; 2004.

8. Gallup Organization. National survey of distracted and drowsy driving attitudes and behaviors: 2002. Washington: National Highway Traffic Safety Administration; 2003.

9. Mitler MM, Miller J C, Lipsitz JJ, Walsh JK, Wylie CD. The sleep of long-haul truck drivers. N Engl J Med 1997; 337: 755-761.

10. Risser MR, Ware JC, Freeman FG. Driving simulation with EEG monitoring in normal and obstructive sleep apnea patients. Sleep 2000; 23: 393-398.

11. Barbe F, Pericas J, Munoz A, Findley L, Anto JM, Agusti AG. Automobile accidents in patients with sleep apnea syndrome. An epidemiological and mechanistic study. Am J Respir Crit Care Med 1998; 158: 18-22.

12. Broughton R, Ghanem Q, Hishikawa $Y$, Sugita $Y$, Nevsimalova $S$, Roth B. Life effects of narcolepsy in 180 patients from North America, Asia and Europe compared to matched controls. Can J Neurol Sci 1981; 8: 299-304.

13. Philip P, Taillard J, Guilleminault C, Quera Salva MA, Bioulac B, Ohayon M. Long distance driving and self-induced sleep deprivation among automobile drivers. Sleep 1999; 22: 475-480.

14. Hakkanen $\mathrm{H}$, Summala $\mathrm{H}$. Sleepiness at work among commercial truck drivers. Sleep 2000; 23: 49-57.

15. Verster J C, Veldhuijzen DS, Volkerts ER. Residual effects of sleep medication on driving ability. Sleep Med Rev 2004; 8: 309-325.

16. Verster J C, Volkerts ER, Schreuder AH, Eijken EJ, van Heuckelum $\mathrm{JH}$, Veldhuijzen DS, et al. Residual effects of middle-of-the-night administration of zaleplon and zolpidem on driving ability, memory functions, and psychomotor performance. J Clin Psychopharmacol 2002; 22: 576-583.

17. Powell NB, Schechtman KB, Riley RW, Li K, Troell R, Guilleminault $C$. The road to danger: the comparative risks of driving while sleepy. Laryngoscope 2001; 111: 887-893. 
18. Horne J A, Reyner LA, Barrett PR. Driving impairment due to sleepiness is exacerbated by low alcohol intake. Occup Environ Med 2003; 60: 689-692.

19. Arnedt J T, Wilde GJ, Munt PW, MacLean AW. How do prolonged wakefulness and alcohol compare in the decrements they produce on a simulated driving task? Accid Anal Prev 2001; 33: 337-344.

20. Horne J, Reyner L. Vehicle accidents related to sleep: a review. Occup Environ Med 1999; 56: 289-294.

21. Brow ID. Driver fatigue. Hum Factors 1994; 36: 298-314.

22. Dinges DF, Gillen KA, Ott GG. Accidents, sleepiness and work hours: a review. In: Akerstedt T, Kecherind G (Editors), Work hours, sleepiness and accidents. Stockolm: Karolinska Institute; 2006. p 5 8.

23. Mello MT, Santana MG, Souza LM, Oliveira PC, Ventura ML, Stampi $C$, et al. Sleep patterns and sleep-related complaints of Brazilian interstate bus drivers. Braz J Med Biol Res 2000; 33: 71-77.

24. Santos $E H$, de Mello MT, Pradella-Hallinan $M$, Luchesi L, Pires $M L$, Tufik S. Sleep and sleepiness among Brazilian shift-working bus drivers. Chronobiol Int 2004; 21: 881-888.

25. Raggatt PT, Morrissey SA. A field study of stress and fatigue in longdistance bus drivers. Behav Med 1997; 23: 122-129.

26. Folkard S. Black times: temporal determinants of transport safety. Accid Anal Prev 1997; 29: 417-430.

27. Folkard S. Effects on performance efficiency. In: Colquhoun WP, Costa G, Folkard S, Knauth P (Editors), Shiftwork: problems and solutions. Frankfurt: Peter Lang; 1996. p 67-87.

28. Steele MT, Ma OJ , Watson WA, Thomas HA J r, Muelleman RL. The occupational risk of motor vehicle collisions for emergency medicine residents. Acad Emerg Med 1999; 6: 1050-1053.

29. U.S. Congress Office of Technology Assessment. Biological rhythms: implications for the worker. Washington: U.S. Government Printing Office, OTA-BA-463; 1991.

30. Sunter D. Working shift - perspectives. Statistics Canada (Catalogue 70-001E) 6-23.

31. Lowden A. J et Lag and Shift-work: their effects on sleep and sleepiness. [Doctoral thesis]. Stockholm: Department of Psychology, Stockholm University; 1998.

32. Presser MB. Toward a 24-hour economy. Science 1999; 284: 11781179.

33. Rutenfranz J, Haider M, Koller M. Occupational health measures for nightworkers and shiftworkers. In: Folkard S, Monk T (Editors), Hours of work: temporal factors in work scheduling. New York: J ohn Wiley; 1985. p 199-210.

34. Guillerminault C, Carskadon M. Relationship between sleep disorders and daytime complaints. In: Koeller WP, Orvin PW (Editors), Sleep. Basel: Karger; 1977. p 95-100.

35. Monk TH. What can the chronobiologist do to help the shift worker? J Biol Rhythms 2000; 15: 86-94.

36. Howard ME, Desai AV, Grunstein RR, Hukins C, Armstrong J G, $\mathrm{J}$ offe $\mathrm{D}$, et al. Sleepiness, sleep-disordered breathing, and accident risk factors in commercial vehicle drivers. Am J Respir Crit Care Med 2004; 170: 1014-1021.

37. Moreno CR, Carvalho FA, Lorenzi C, Matuzaki LS, Prezotti S, Bighetti $P$, et al. High risk for obstructive sleep apnea in truck drivers estimated by the Berlin questionnaire: prevalence and associated factors. Chronobiol Int 2004; 21: 871-879.

38. George CF. Reduction in motor vehicle collisions following treatment of sleep apnoea with nasal CPAP. Thorax 2001; 56: 508-512.

39. Haraldsson PO, Carenfelt $\mathrm{C}$, Laurell $\mathrm{H}$, Tornros J. Driving vigilance simulator test. Acta Otolaryngol 1990; 110: 136-140.

40. Carter N, Ulfberg J, Nystrom B, Edling C. Sleep debt, sleepiness and accidents among males in the general population and male professional drivers. Accid Anal Prev 2003; 35: 613-617.

41. Harma M. Sleepiness and shiftwork: individual differences. J Sleep Res 1995; 4: 57-61.

42. Cummings $P$, Koepsell TD, Moffat JM, Rivara FP. Drowsiness, counter-measures to drowsiness, and the risk of a motor vehicle crash. Inj Prev 2001; 7: 194-199.

43. Macchi MM, Boulos Z, Ranney T, Simmons L, Campbell SS. Effects of an afternoon nap on nighttime alertness and performance in longhaul drivers. Accid Anal Prev 2002; 34: 825-834.

44. Rosekind MR, Smith RM, Miller DL, Co EL, Gregory KB, Webbon $\mathrm{LL}$, et al. Alertness management: strategic naps in operational settings. J Sleep Res 1995; 4: 62-66.

45. Muzet A, Nicolas A, Tassi P, Dewasmes G, Bonneau A. Implementation of napping in industry and the problem of sleep inertia. J Sleep Res 1995; 4: 67-69.

46. Haslam DR. Sleep deprivation and naps. Behav Res Methods Instrum Comput 1985; 17: 46-54.

47. Dinges DF, Orne MT, Orne EC. Assessing performance upon abrupt awakening from nap driving quasi-continuous operations. Behav Res Methods Instrum Comput 1985; 17: 37-45.

48. Matsumoto K. Effects of nighttime naps on body temperature changes, sleep patterns, and self-evaluation of sleep. J Hum Ergol 1981; 10: 173-184.

49. Balkin TJ, Badia P. Relationship between sleep inertia and sleepiness: cumulative effects of four nights of sleep disruption/restriction on performance following abrupt nocturnal awakenings. Biol Psychol 1988; 27: 245-258.

50. De Valck E, De Groot E, Cluydts R. Effects of slow-release caffeine and a nap on driving simulator performance after partial sleep deprivation. Percept Mot Skills 2003; 96: 67-78.

51. Walsh J K, Muehlbach MJ, Schweitzer PK. Hypnotics and caffeine as countermeasures for shiftwork-related sleepiness and sleep disturbance. J Sleep Res 1995; 4: 80-83.

52. Wesnes K, Warburton DM. Effects of temazepam on sleep quality and subsequent mental efficiency under normal sleeping conditions and following delayed sleep onset. Neuropsychobiology 1986; 15: 187-191.

53. Moon CA, Hindmarch I, Holland RL. The effect of zopiclone $7.5 \mathrm{mg}$ on the sleep, mood and performance of shift workers. Int Clin Psychopharmacol 1990; 5 (Suppl 2): 79-83.

54. Hart CL, Ward AS, Haney M, Foltin RW. Zolpidem-related effects on performance and mood during simulated night-shift work. Exp Clin Psychopharmacol 2003; 11: 259-268.

55. Reilly $T$, Atkinson G, Budgett R. Effect of low-dose temazepam on physiological variables and performance tests following a westerly flight across five time zones. Int J Sports Med 2001; 22: 166-174.

56. Banerjee D, Vitiello MV, Grunstein RR. Pharmacotherapy for excessive daytime sleepiness. Sleep Med Rev 2004; 8: 339-354.

57. O'connor PJ, Youngstedt SD. Influence of exercise on human sleep. Exerc Sport Sci Rev 1995; 23: 105-134.

58. Martins PJF, Mello MT, Tufik S. Exercício e sono. Rev Bras Med Esporte 2001; 7: 28-36.

59. Vesentini L, Van Vlierden K, Cuyvers R. Vermoeidheid in het verkeer. Rapport RA-2003-26. Diepenbeek: Steunpunt Verkeersveiligheid bij Stijgende Mobiliteit; 2003. 